\title{
Taoist Humanities and Re-enlightenment
}

\author{
YU Ru-song \\ Shandong University, Jinan, China
}

\begin{abstract}
Both humanities and reason in the modern context have direct connection with the Enlightenment. At the beginning, the Enlightenment of modern Europe had to some extent benefited from the light of reason in Taoist organic naturalism. However, as it expanded, Western rationalism experienced lack of counterbalance from humanities in the Western culture. As a result, the Enlightenment has not brought a healthy civilization as initially anticipated, and has made human nature forfeit once more in the new authority of rationalism. Facing the morbid or gray civilization brought by the Enlightenment, Taoism, which is rich in the spirit of humanistic concern and humanistic reason, will certainly once again become a beacon of the Re-enlightenment.
\end{abstract}

Keywords: Taoism, humanistic concern, humanistic reason, re-enlightenment

Humanities and reason in the modern context are both direct products of the Enlightenment, and they had once acted as the primary means or goal of the Enlightenment. The core objective of the Enlightenment was to use the humanistic spirit and the light of reason to oppose the obscurantism of the divinity which had enslaved human nature over a long period of time, and to enable human-oriented as a new purport of civilization. However, the over-highlighting of reason in the course of the Enlightenment has resulted in the missing of humanistic concern and has caused human nature to forfeit once more to the new authority of rationalism. At most, the Enlightenment brought the human being from the medieval dark ages into the modern gray world, and humans are still living in the morbid civilization. Therefore, the re-enlightenment of humanities-oriented is imperative. Taoism, as a kind of unique wisdom of inspiration, had benefited the Enlightenment with the light of reason in its organic naturalism. In facing the current crises human encounters, Taoism, which is rich in the spirit of humanistic concern and humanistic reason, will certainly become a beacon of the Re-enlightenment once again.

\section{Taoist Humanistic Concern}

Because of Taoist unique tenet that Tao of immortal loves lives with special respect, and its telos is just to convert immeasurable people to be immortal, ${ }^{1}$ Taoism becomes the only humanistic religion among all the world's major religions that has human life as its direct caring object. Taoist humanistic concern can be generally described as human-ontologized, human-respected and life-beloved, respecting human subjectivity and creativity, and endowing lives with Taoist ultimate concern.

First, Taoist humanistic concern is manifested to give the secular human an equal importance with the holy ultimate reality of Tao. Tao is the ultimate existence and the foundation of all the theories of Taoism. Taoism

YU Ru-song, doctor of Chinese Philosophy, Associate Professor, School of History and Culture, Shandong University.

${ }^{1}$ Tao Tsang, Volume 1, p. 60. 
thinks that there are four supreme existences in the universe and Man is one of them. Tao Te Ching states: "Tao is supreme, Heaven is supreme, Earth is supreme, and Man is supreme. There are four supreme existences in the universe, and Man becomes one of them."” From Taoist views, human life is just another kind of manifestation of the ultimate reality of Tao, that is, life equals Tao. Laozi Xianger Zhu says: Life is just another form of Tao. ${ }^{3}$ Tai Shang Lao Jun Nei Guan Jing notes: Tao is invisible without life’s show; life is impermanent without Tao’s protection. Tao is worthless as life disappears and vice versa. "Only when life is unified with Tao as one can it live forever."

It can be easily seen that at the ages of obscurantism when Being was often worshipped as supreme god and universally regarded to be holy and transcendental, while Man as product of Being was just humble secular, Taoism demonstrated a different kind of typical commendable humanistic concern for its humanities of human-ontologized, human beloved and respected, and devoting the unity of human and ultimate Tao.

Second, Taoism thinks that human life is the most invaluable of all the lives of living creatures. Tai Ping Jing points out: There are 12,000 kinds of lives in the universe, but human life is the most valuable (WANG, 1960, p. 34). Bing Shou Zhang tries to analyze the reason for this: Human life comes out of the heaven and earth, endowing the essence of the heaven and earth's coition, crowning ahead of myriad things, ranking upon the most spiritual place, covering the quintessence of Wu-Xing (five basic elements to form everything in Chinese Philosophy), participating in the heaven and earth to become San-Cai (the whole cosmic system consisted of the heaven, the earth and human in Chinese Philosophy), and getting the equal virtue and function with the heaven and earth. How can human not be valuable? ${ }^{5}$ Yang Xing Yan Ming Lu also states: Of all the things which are endowed in breath and spirit, only human is valuable. It is the life in human things that is the most valuable. $^{6}$ And so, Man should love, exercise and take good care of his life positively and initiatively, and therefore, Taoism establishes its religious fundamental purpose of respecting human and valuing life. Tao Te Ching states: "The reason why I have awful anxieties is that I still have my life. If I have no life, what anxiety can I have? So the one who values his life as the world, can be mandated with the world, and the one who loves his life as the world, can be entrusted with the world." So, Taoist life concerns can be summed up as: Life is Man's most valuable asset, which is worth paying his full attention, and loves to keep it. Enjoying life is enjoying everything, and losing life is losing everything.

Finally, in the self-help of life caring, Taoism rejects fatalism, but encourages the development of Man's subject consciousness, initiative and creative spirit. Taoism thinks that in the realization of the ultimate value of life, Man's opportunities are equal, and no one has a priori superiority or destined privileges. In terms of the ultimate ideal of Taoist longevity and immortal, Bao Pu Zi Nei Pian states: Longevity is known to be possible to everyone and immortal isn't endowed to one who is destined to receive it. My life is in the charge of my hand, not in the destiny. If life was practiced with the Golden Elixir, it could last for millions of years (WANG, 1985, pp. 110, 287). Taoism stresses that in loving one's life, one must break the stereotypes of life and exert his

\footnotetext{
2 Tao Te Ching, 25.

3 Zhonghua Tao Tsang, Volume 9, p. 178.

4 Tao Tsang, Volume 11, p. 397.

5 Tao Tsang, Volume 22, p 211.

6 Tao Tsang, Volume 18, p 474.

7 Tao Te Ching, 13.
} 
initiative spirit to practice his life perfectly. Xi Sheng Jing says: My life is controlled by myself, not controlled by gods from the heaven. In terms of this, long or short lived life is entirely up to my own practice and responsibility, and has nothing to do with god's gift and others' depredation. ${ }^{8}$

As far as the exerting one's subjective initiative, on the one hand, Taoism emphasizes to obey natural laws first; then to make up his mind and try his best, that is, God's gift is natural, while Man's wish is done by himself. ${ }^{9}$ On the other hand, Taoism realizes the importance of Man’s creativity and eulogizes it enthusiastically. Wen Shi Zhen Jing states: Man's power can change what nature creates, such as thundering in winter, icing in summer, dead body walking and dead wood flowering. ${ }^{10}$ Tao Te Ching clearly opposes to the following of philistinism and conformity with the masses, which will surely kill his personality, but supports the development of a creative scientific spirit of independence that is different from others. "The world look bright, while I alone seem to be benighted. The world look full of discrimination, while I alone seem to be confused. I seem to be carried about as on the sea, drifting as if I had nowhere to rest. The world all look to have their ways to act, while I alone seem intractable and boorish. What I am different from the world is that I originally know what the Mother Tao looks like and just follow as Tao does."11

\section{Taoist Humanistic Reason}

Nature or no action (contrary to Nature) is the basic principle and maximum program of Taoist theories and practices, so it is the important content of Taoist humanistic reason. Nature or no action means acting just as everything is allowed to do naturally, without attempting to exert force in human affairs, which actually doesn't mean doing nothing and keeping silent, understood in a philistine way. Taoism says: Action which follows the nature of everything happens, but it is still thought to be no action (contrary to Nature). ${ }^{12}$ Joseph Needham (1990) points out: Non-action in Taoism means refraining from activity contrary to Nature. In other words, refraining from going against the nature of things willfully, and from trying to make things perform functions for which they are unsuitable (p. 76).

Taoist humanistic reason can be described as objecting to using the oddity of instrumental rationality one-sidedly to mislead human desires and harm human nature. The profound connotation of Taoist humanistic reason can be appreciated from the fable told in Tian-Di of Chuang-tzu:

Zi Gong traveled south to Chu. As he came back from Jin, in Han Yin, he saw an old gardener preparing his fields. He made his way to enter the well, from which he carried a pitcher of water in his arms to water the fields. He really spent lots of energy, but produced little results. Zi Gong said: "A machine has been invented which can water a hundred fields in a day, demanding less effort, but getting more efficiency. Wouldn’t you know that?” ...

The gardener flushed with anger and then said with a laugh:

I've heard my teacher say, where there are machines, there are bound to have difficulties in machines; where there are difficulties in machines, there are bound to be machine worries in mind; With a machine worries in your mind, your mind is no longer pure and simple; if your mind is no longer pure and simple, your spirit and life will be unsettled; if your

\footnotetext{
8 Tao Tsang, Volume 22, p. 643.

9 Tao Tsang, Volume18, p. 476.

${ }^{10}$ Tao Tsang, Volume 11, p. 522.

11 Tao Te Ching 13.

12 Tao Tsang, Volume 11, p. 753.
} 
spirit and life are unsettled, you will be away from Tao. It's not that I am not aware of the machine, but that I should be ashamed to use it. ${ }^{13}$

This fable tells us that instrumental rationality will make human dissimilation be the object of machines, and humans will finally lose their nature and apart from the ultimate concern—Tao. Taoism thinks that the strange tricks and wicked craft skills always become the root of stimulating human desire, which is the most dangerous enemy to destroy human nature. Tao Te Ching states: The more sharp weapons there are, the more benighted the state will grow; the more cunning craftsmen there are, the more pernicious contrivances will be invented. ${ }^{14}$ John Dewey (1965) points out: Science and technology are not the cosmic force of impersonalization, which can only take effects in the media of human desire, foresight, purpose and effort (p. 23).

Instrumental rationality is sure to swell human desires, harm human nature and make humans stray from Tao's ultimate concern. Taoists think desire, which is the form of human nature's restlessness, is driven by certain circumstance and comes into being in the mind. If there is no desire in the human mind, human nature is pure and peaceful, which could reflect the ultimate Tao and see the wonderful origin. If there is desire, which is chasing after the supposed circumstance and stirring in the mind, the pure and peaceful nature will be upset. If the original Tao is contemplated in the desired nature, it must not only be disharmonious, but also biased. ${ }^{15}$ The burning desire which comes from one's mind, finally makes his body and mind disgraced and destroyed. Because of lust, Man is making himself enslaved by the things he tries to go in for. Besides, in the argument on nature and desire, Taoist also clearly points out: The limited life really has its end, but the growing desire is definitely infinite. Using the limited life to chase after the endless desire is too much like committing suicide. ${ }^{16}$ Therefore, Taoists advocate going with the nature and lessening the desires, and objecting to making use of the instrumental reason to fill the harmful desires so as to hurt human life and nature and bring to human unnecessary disasters or tragedies. Just as Chuang-tzu warns: Duck's leg is short, but lengthening it will cause anxiety. Crane's leg is long, but shortening it will cause misery. Therefore, what nature has made long shouldn't be shortened, and what nature has made short shouldn't be lengthened. Following the nature without perverse desire would be no sorrow. ${ }^{17}$

So, could Taoist human reason be turned into an irrationalism of blindly spurning instrumental reason like giving up eating for fear of choking? No. What Taoism is up against is actually not the instrumental reason itself, but its misapplication. In the application of instrumental reason, Taoism has a higher requirement, namely, the unity of technology and Tao, which means when technology is put into use, it should just do good and not harm to humans, embodying its ultimate concern. The fable "Cook Ting Cutting up Oxen" told in Yang Sheng Zhu of Chuang-tzu can clearly demonstrate the viewpoint of Taoist uniting of technology and Tao:

Cook Ting was cutting up an ox for Lord Wen-hui. Every touch of his hand, every heave of his shoulder, every move of his feet, every thrust of his knee,...All was in perfect rhythm, as though he were performing the dance of the Mulberry Grove or the harmonious chords of Ching Shou.

\footnotetext{
13 Tian-Di of Chuang-tzu.

${ }^{14}$ Tao Te Ching 57.

15 Tao Tsang, Volume11, P750.

16 Tao Tsang, Volume22, P386.

17 Pian Mu of Zhuangzi.
} 
“Oh, excellent!” cried Lord Wen-hui. “How did you come up with such a perfect technique?”

Cook Ting laid down his knife and replied, "What I am fond of is Tao, and it has been with my techniques. ... Nowadays, I sense with my spirit instead of looking with my eyes. My perception has come to a stop and my spirit moves where it wants. It is because I go along with the natural makeup, strike in the big hollows, guide the knife through the big openings, and follow things as they are. So I never touch the smallest ligament or tendon, much less a main joint." 18

This fable tries to say that technology has its own natural laws and fundamental principles of application. Techniques should be with Tao, "go along with the natural makeup", and "follow things as they are", and not follow human desire of reason. Such techniques would not only be perfect just like arts to bring human sense of beauty, but also be humanistic concern to benefit human without any harm. Besides, the fable also reminds us that there are forbidden zones in the use of technology, sometimes, some technology may be in the zone of "never touch".

Therefore, Taoism thinks that techniques should be the products of the unity of technology and Tao, the invention and application of technology should be fully filled with humanistic concern, blending together the external instrumental rationality and the inherent ultimate concern. Taoism clearly realizes that technical reason has the function of the double-edged sword and human alienation. So Taoism strongly depreciates the instrumental reason, which depends on human desires, but highly praises the one that goes along with the natural makeup, follows things as they are.

Joseph Needham (2001), who quite understood Taoist wisdom of humanistic reason, said:

Taoism respects the techniques of physical work, adopts the empiricism viewpoint, trusts and appreciates the dexterity and ingenuity of the mechanics and the inventors, but sometimes it paradoxically expresses its opposition to the scientific and technological innovation. ... However, after closely scrutinizing their elaboration, we discovered that what Taoism opposes is technical misusing, rather than the technology itself. (p. 113)

Therefore, as indicated previously, Taoist viewpoints of technology is the ultimate technology of Tao: Not too gentle, not too hard-you can get it in your hand and feel it in your mind. You can't put it into words, and yet there's a knack to it somehow. It can't be taught or learnt. ${ }^{19}$ Such technical reason is linked with Taoist ultimate concern-Tao, which is doing good without harm, so it is really a true humanistic reason.

\section{Taoism Is the Organic Combination of Humanities and Reason}

Taoist religious ideals and realistic affections of respecting human and valuing life make it sense that Taoism in itself contains the unique religious humanistic concern and the humanistic rational spirit. It's easy to understand that Taoist humanistic concern stems from its religious attribute. Essentially, religion is an important source of human concern. Religion is also one field of the humanities world, and in the most extensive and most fundamental sense, religion is a kind of ultimate concern. This ultimate concern is to transcend the relative to reach the absolute, to transcend the ephemeral to reach the eternal, to transcend the defect to reach the perfect. Moreover, Taoism always takes it as its religion-created goal to promote all-round healthy development of human, and takes it as its religion-depended to enhance human realms of body and mind. Therefore, Taoism is

\footnotetext{
18 Yang Sheng Zhu of Chuang-tzu.

19 Tian-Tao of Zhuangzi.
} 
likely to contain more spirit of humanistic concern than other religions.

Besides, in the process of Taoist pursuing longevity and immortal, Taoism consciously puts the spirit of scientific rationality into practice. Feng Youlan (1985) states: Taoism has the scientific spirit of conquering nature. People who are interested in history of science can find many materials in Taoists' writings (p. 6). Qu Jigao (1989) thinks: Burning the lead and refining the mercury, medicine and martial arts in Tao Tsang are all no less than the science; even some tricks the former alchemists played can be gradually proved by science (p. 726). Zhu Yaping (1995) states: Taoist practice is carried out basically around the theme to explore the nature, the life and human inner world. Therefore, some of the activities are consciously or unconsciously certain kinds of the science and technology (p. 30).

Taoist cosmology is the theoretical basis and concentrated expression of Taoist religious concern and rational spirit melting together. In the generation of the universe, Taoism sets Tao, which is abstract, absolute and beyond of human, as the noumenon of the world. Tao Te Ching states: Tao appears to be the origin of everything. Nobody can know its source, and it is like a prelude to nature, a preface to God. ${ }^{20}$ It may be regarded as the Mother of all things. Nobody can know its name, and it is given the designation of the Tao. ${ }^{21}$ In Taoist opinion, everything (including humans) in the universe is not created by gods, but is generated from Tao. Taoism not only liberates humans from gods' authority of theology, but also endues humans with the equal worshipful ontological status with Tao, which might be regarded as Taoist prehistoric Renaissance in China. Besides, in epistemology, Taoism forwards a kind of scientific cognitive principle of "Man follows the laws of the earth, the earth follows the laws of the universe, the universe follows the laws of Tao, and Tao follows the laws of its own nature." 22 Namely, Taoism sets Tao, independent from the outside of human subjective consciousness, as originality of the world and guideline of the actions. This leads to two significances in Taoist epistemology: On the one hand, Taoism emphasizes that only by following the objective laws to act, can humans preserve themselves from hurt, and achieve their maximum benefits. On the other hand, Taoism defines the world generated from Tao as its cognitive direct objects, which lays a strong scientific foundation of Taoist science understanding.

Albert Einstein points out: It is the foundation of all natural sciences to believe an independent outside world beyond the perceptual subject. ${ }^{23}$ Zhu Yaping (1995) thinks: Taoism which regards Tao as the noumenon of the world and the beginning of the universe, has no color of creationism absolutely, which is undoubtedly of scientific significance more than 2,000 years ago (p. 72).

All in all, Taoism is full of not only humanistic concern, but also rational spirit, and becomes an organic combination of humanities and reason.

\section{Taoism Is the Wisdom Bank of Enlightenment}

As far as the meaning of enlightenment and internationalization in Chinese culture, Taoism is the best achievement of civilization. Taoist immanent unique humanistic concern and humanistic rational spirit has been

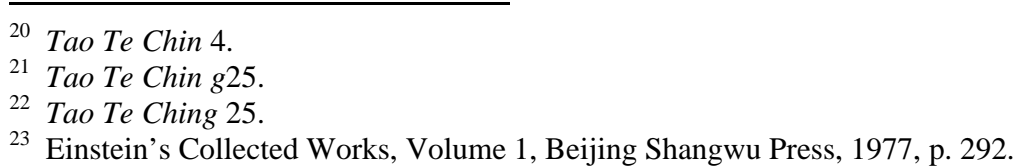


considered to be a world-class culture which can alone compare favorably with the enlightenment philosophy of ancient Greece. Joseph Needham (2001) points out explicitly that Taoist ideological system which is a unique intermixture of philosophy and religion, and contains the primitive science and the side technique as well, is the only system of mysticism in the world that does not extremely oppose science (p. 92). Taoists have many similarities to the scientific philosophers of the schools of Greek pre-Socratic and Epicurean. Taoist studies and insights on the nature can compare favorably with Greek thoughts before Aristotle, which makes it become the foundation of the entire Chinese science (Needham, 1990, pp. 175, 1).

In 16th-18th centuries, Taoist rational thought of organic naturalism, with the help of Western culture messengers' absorption and propagation, had become an important source of enlightenment. It was said that by assembling the essences of Chinese and Western Culture, Leibniz's Monadology put forward creatively as the theoretical system of individual maintaining independence and whole keeping harmony, and became a bright phosphor of the Enlightenment. Joseph Needham appreciates that Taoist philosophy of naturalism contains rich organistic thoughts. If China's organistic world schema was really transmitted by the medium of Leibniz and translated into the new western philosophy thought at that time, well then, it is never too high to value its importance (Needham, 1990, p. 528). Shen Dingping (1983) thinks: Leibniz regarded Chinese culture as a giant thinking stick of the Enlightenment. He was the first to open this kind of door for the later enlightenment thinkers to rely on the help of Chinese civilization to whip the old European tradition. Shen Fuwei (1985) thinks: In the time of the flourishing development of the Enlightenment, the outstanding Chinese culture had ever given the rich nourishment to Leibniz's classical speculative philosophy, and urged the birth of modern European civilization (p. 448).

Since the Enlightenment, instrument reason has been extremely inflated, while value reason has been seriously deficient. On the one hand, the creativity of instrument reason has already blinded human critical wisdom eyes, and even Science has been consecrated as a new god to be revered and in which to have faith. John Dewey claimed: Man has given the science a childlike trust, and hasn't realized the development of science itself is still in the time of infancy. The methods of scientific research have not reached its maturation period. The science cannot be extended to all aspects of all human life (Dewey, 1965, p. 7).

What is worse, instrument reason is rapidly growing to be an authority mostly based on the criticism of religion, which lacks in itself the proper humanities spirit and ultimate concern due to the traditional religions, so that instrument reason never considers the consequences in the process of its linear development, and is also never responsible for the consequences done to human. The end results must be that technical reason often urged by the mechanism of direct realistic interest, benefits only a small number of people, but its destructive negative influences will impact all mankind. Technical reason must be self-defeating due to the loss of the value of self-existence in the development of its self expansion.

On the other hand, the development of instrument reason regardless of the value reason and ultimate concern, will inevitably lead to the alienation and harm to human nature, and violate its original intention of benefiting mankind, for Sci-Tech reason by no means is the only need of humanity. Technical reason has never allowed humans to exist as a whole; no matter as a technical designer, master or operator, humans have already alienated the dolls for technology. In General Preface of Science is facing a crisis: the humanities reflection on modern science and technology, Wu Guangyuan (2005) says: the highly developed modern science and 
technology is leading humans as well as the human culture to a world which is full of unfamiliar, indifferent, dark, and crisis-ridden. Facing formidable science and technology, Man feels helpless, frightened and trembling (p. 4). George Murphy (2002) also points out: "One of the most powerful challenges, formed by the rise of modern science, may be that human's understanding merely restricts in the mundane reality, but forgets the ultimate reality entirely” (p. 137).

Instrument reason which has a mechanical mechanism and lacks the humanities spirit, rescues humanity from the religious obscurantism, and at the same time, shuts humanity into its cage of rationalization and stylization. Humanity has once again lost its nature, and become a morbid, sugared up with self-intoxicated mechanical corpse. One day, humanity will suffocate to death in this cage. The Enlightenment has not brought mankind the civilization as intended, at best it is just a morbid civilization, a gray civilization, which in itself needs to carry on a further re-enlightenment with the humanities wisdom.

Taoist scientific rational spirit, such as observing the natural laws and following it to act, will be perfect, ${ }^{24}$ and exploring the arcane truth of the universe and knowing the principles of the creation, ${ }^{25}$ as well as the organic united spirit of instrument reason and value reason, such as everything done not going against, but in line with, the natural laws and human wills, will bring human peaceful heart and pleased will, ${ }^{26}$ has made Taoism be full of resources of rich humanistic concern and humanistic reason. Taoist great thought and true knowledge has been causing a close attention of the Chinese and Western scholars, and it is bound to live up to expectations in shouldering the historical task of re-enlightenment, unceasingly providing the inspiration wisdom to promote the healthy growth of human civilization.

Ding Yuanming (2002) points out: Contemporary scholars of East and West in the settlement of the combination of science and humanities, as well as the social problems of sharp confrontation of humanity and nature in the post-industrial society, turned their visual field to Eastern thought, especially to Taoism, which illustrated sufficiently that Taoist thought has a great reference value in the construction of contemporary scientific humanism (p. 59).

In advocating the reversion of unifying the science-technology and humanities, Li Yuanguo (2001) points out: This reversion is not only a kind of worldwide renaissance for Chinese traditional culture, but also a kind of new enlightenment, because such reversion requires self-criticism of modern culture. Of course the purpose of this self-criticism is not to bury rationality and science, but to develop and improve rationality and science. But the future development will surely not continue along the line determined in the seventeenth century to advance, it is likely to use Chinese Taoist intelligence for reference to open up new paths. The reversion of the views of modern science to some extent, to Taoism thought, has manifested this historical developing tendency (p. 15).

\section{Conclusion}

The Enlightenment enabled people to gradually emancipate themselves from the limits of the theological obscuration and domination of nature, by virtue of their own rationalization. Since then, reason has become the means and purpose for which man conquers everything, and man has become the center of the universe. The

\footnotetext{
24 Tao Tsang, Volume 1, p. 821.

25 Tao Tsang, Volume 18, p 671.

26 Taoist Writings out of Tao Tsang, Volume 12, p. 88.
} 
Enlightenment made the instrumental reason extremely inflated and the value rationality was seriously lacking. While enjoying the tremendous achievements engendered by the Enlightenment, people are also bearing its bitter fruits.The linear development of instrumental rationality and the endless greed of human beings have fallen into a vicious cycle that is hard to extricate themselves; and there has also been an unprecedented disharmony between man and nature. Human value and humanistic care have been lost in the constant promotion of Enlightenment rationality; reason becomes the new God of man, which makes people fall into the fence of their own reason, and become the object of obedience and zombies without soul.

Taoism is an oriental culture, closely linked with religion and Philosophy, and its doctrines of human-respected and life-beloved, following nature or no action (contrary to nature), show extremely rich religious care and philosophical rational spirit. Taoism insists on people-oriented, and thinks that instrumental rationality bewitches human desire and destroys human nature. Therefore, Taoism, on the one hand, opposes the misuse of instrumental rationality; on the other hand, advocates that instrumental rationality should take into account the value rationality in the service of human nature's needs, which shows Taoist unique humanistic care and humanistic spirit. Facing the numerous perplexities and crises that human beings have encountered since the Enlightenment, Taoist functions of enlightening and rectifying the Enlightenment rationality, have become a broad consensus, so we have every reason to believe that the humanistic care and humanistic reason of Taoist spirit will surely become the source of wisdom for the re-enlightenment of human civilization.

\section{References}

Chuang-tzu. (1998). Exegesis of Nanhua Zhenching. Beijing: Zhonghua shuju Press.

Dewey, J. (1965). Problems of men (Chinese Version). Shanghai: Shanghai People’s Press.

DING, Y. M. (2002). Taoist scientific spirit and humanities spirit. Literature, History and Philosophy, (1), 59.

Einstein's collected works (Vol. 1) (p. 292) (1977). Beijing: Beijing Shangwu Press.

FENG, Y. L. (1985). Brief history of Chinese philosophy (p. 6). Beijing: Peking University Press.

HAN, X. C. (2005) Science is facing a crisis: The humanities reflection on modern science and technology. Beijing: Society Press of China.

Lao-tzu. (1994). Tao Te Ching. Changsha: Press of Hunan.

LI, Y. G. (2001). The modern explanation on the view of Tao following the nature. Compiled papers of Chinese Taoist culture seminar in Maoshan (p. 15). Beijing: Institute of Taoist culture in China Taoist Association.

Needham, J. (1990). The history of Chinese science and technology (Vol. II) (Chinese Version). Beijing and Shanghai: Science Press and Shanghai Ancient Books Press.

Needham, J. (2001). The history of chinese science and civilization (Vol. I) (Chinese Version). Shanghai: Shanghai People’s Press.

Peters, T., Seng, K. P., \& Bennett, G. (2002). Bridging science and religion (Chinese Version) (p. 137). Beijing: China Social Science Press, ,.

QU, J. G. (1989). Brief research on Tao Tsang, enclosed in selections of Tao Tsang classical writings (Vol. 10) (p. 726). Shanghai: Shanghai ancient books Press.

SHEN, D. P. (1983). Chinese ancient thoughts and the development of Western European enlightenment. World History, (2), 26.

SHEN, F. W. (1985). The History of Chinese and Western cultural exchange (p. 448). Shanghai: Shanghai People’s Press.

Tao Tsang. (1987). Shanghai, Beijing and Tianjin: Shanghai Bookstore Press, Cultural Relics Publishing House, Tianjin Ancient Books Publishing House.

WANG, M. (1960). Tai Ping Jing Hejiao (p. 34). Beijing: Zhonghua shuju Press.

WANG, M. (1985). Bao Pu Zi Nei Pian Jiaoshi (pp. 110, 287). Beijing: Zhonghua shuju Press.

Zhonghua Tao Tsang. (2004). Beijing: Huaxia Press.

ZHU, Y. P. (1995). Taoist culture and science. Hefei: University of Science and Technology of China Press. 